\title{
INTEGRANTES DE MOVIMENTOS LGBT+ E ENFRENTAMENTO DA LGBTFOBIA
}

LGBT+ MOVEMENTS MEMBERS AND COPING WITH LGBTPHOBIA

Rafael De Tilio', Flávia Gomes Silveira²

RECEBIDO EM: 25/09/2018 | ACEITO EM: 06/03/2019

DOI: $10.5902 / 2317175834922$

\section{RESUMO}

O objetivo dessa pesquisa foi compreender como integrantes de movimentos LGBT+ lidam (significam e enfrentam) com a LGBTfobia. Seis participantes (jovens adultos, entre 21 e 29 anos, cursando ensino superior) de uma organização não-governamental e de um coletivo de ativismo LGBT+ na região do Triângulo Mineiro foram entrevistados. Os dados foram organizados em três categorias a partir de uma análise de conteúdo temática pautada na perspectiva foucaultiana e destacam-se os seguintes resultados: os inúmeros impactos pessoais e profissionais ocasionados por este tipo de violência quando do coming out e a importância de participação em movimentos sociais como estratégias de proteção e busca por efetivação dos direitos. Reitera-se a necessidade da constituição de redes de apoio à comunidade não cisheterossexual como forma de combate às violências visando a implementação de direitos humanos para grupos de minorias.

Palavras-Chave: Sexualidade; Homofobia; Minorias sexuais; Direitos humanos.

1 Docente do Departamento de Psicologia e do Programa de Pós-graduação em Psicologia da UFTM. ORCID iD: http://orcid.org/0000-0002-4240-9707

Instituição/ Afiliação: Universidade Federal do Triângulo Mineiro. Brasil 2 Psicóloga

ORCID iD: http://orcid.org/0000-0002-0777-9497

Instituição/ Afiliação: Universidade Federal do Triângulo Mineiro. Brasil 


\begin{abstract}
The objective of this research was to understand how members of LGBT+ movements deal with LGBTphobia. Six participants (young adults between 21 and 29 years old) from a non-governmental organization and an empowerment group linked to LGBT+ activism in the Triângulo Mineiro (Brazil) region were interviewed. The data were organized into three categories based on an analysis of thematic content based on the foucaultian perspective, and the main results highlights: the numerous personal and professional impacts caused by this type of violence in the coming out process and the importance of participation in social movements as strategies of protection and search for effective rights. It reiterates the need to establish support networks for the non cisheterossexual community as strategy to face violence and endorsement of human rights.
\end{abstract}

Keywords: Sexuality; Homophobia; Sexual minorities; Human rights.

\title{
1 Introdução
}

As pessoas que possuem identidades de gênero ${ }^{3}$ e as orientações sexuais $^{4}$ não cisheterossexuais (adequação entre sexo biológico e papéis de gênero numa orientação heterossexual) são consideradas disruptivas e passíveis de diversas intervenções. Por exemplo, segundo Freire e Cardinali (2012), a homossexualidade, a bissexualidade, a assexualidade e as transgeneridades foram (e são) rechaçadas e condenadas de diferentes formas ao mesmo tempo em que, a partir da década de 1960, passaram a se organizar em lutas políticas com o intuito de conquistar espaço no cenário político e social. Isso permitiu o ingresso (mas nem sempre a aceitação) das suas demandas no debate político em busca de direitos individuais e sociais.

Neste sentido, cabe destacar que a cisheterossexualidade é um fenômeno sociopolítico relativamente recente, porém, revestido de status de normalidade - o que nem sempre foi a tônica na história (FRY e MAC RAE, 1991; SILVA 2003). Isso ilustraria como as pessoas performatizam sua(s) sexualidade(s) em contextos culturais específicos, haja vista que a vivência da sexualidade está relacionada às prédicas (práticas e discursos) socialmente organizadas e estabelecidas por intermédio de relações de poder, não sendo meros reflexos dos imperativos biológicos. Foucault (2014) argumenta que a sexualidade se relaciona com a produção do saber e com o exercício do poder, não devendo ser considerada como determinada unicamente pela biologia dos corpos, mas sim

3 Identidade de gênero é um conceito que diz respeito ao gênero (masculino, feminino) com o qual a pessoa se identifica em relação ao sexo biológico (macho, fêmea) atribuído ao nascimento. Se a pessoa identifica seu gênero como adequado ao sexo trata-se de cisgeneridade; se a pessoa não identifica seu gênero com o sexo trata-se de transgeneridade (que engloba, dentre outros, travestis, transgêneros, dragqueens, drag king e genderfluids).

4 Orientação sexual diz respeito por quais gêneros a pessoa sente atração física, romântica e emocional, sendo independe da identidade de gênero, podendo ser (basicamente) heterossexual, homossexual, bissexual ou assexual. 
que na modernidade ocidental o discurso biológico foi utilizado para afirmar a cisheterossexualidade como normalidade em detrimento de outras possibilidades não cisheterossexuais.

Se a cisheterossexualidade estabeleceu regimes de adequações aos quais parte da população se adéqua, contudo, os que não se enquadram estão sujeitos aos regimes disciplinares específicos, marginalização e vulnerabilidade social e aos efeitos do extensivo controle social (SPARGO, 2017). Grande parte - se não todas - das sociedades ocidentais tem discriminado de diversas maneiras os homossexuais, bissexuais, transexuais, transgêneros e travestis por considerá-los não adaptados à cisheteronormatividade preconizada pelos estratos dominantes. Obviamente, diante dessa recusa são estabelecidas resistências. Recentemente e cada vez mais a militância política e a resistência contra as violências físicas e psicológicas contra a população LGBT+ (lésbicas, gays, bissexuais, assexuais, travestis, intersexuais, assexuais, transexuais e transgêneros) tem ganhado visibilidade, inclusive no Brasil. Visibilidade significa:

Tornar visível algo que foi estrategicamente ocultado. Pode-se referir a tornar visível desde elementos identitários de uma vivência individual, nos âmbitos privado ou público, até elementos identitários partilhados coletivamente com vistas a produzir uma identidade política, interpelar a vida pública e inserir demandas na agenda política de uma sociedade (PRADO e MACHADO, 2012, p. 144).

Assim, segundo Santos (2010) foi importante tornar a homossexualidade e a(s) transgeneridade(s) visíveis à sociedade brasileira - que é tradicional, conservadora e preconceituosa quanto a sexualidade e gênero - possibilitando a formação de grupos em defesa e o acirramento dos debates de direitos acerca das minorias sexuais. Além disso, segundo Gouveia e Camino (2009) deve-se considerar os importantes debates sobre HIVIAIDS (inicialmente associados aos homossexuais), sobre violência de gênero e sobre direitos sexuais e reprodutivos. Essa crescente visibilidade visava e visa combater a homofobia e a transfobia, conceituadas como sendo o ódio e à aversão aos homossexuais, bissexuais, travestis, transexuais e transgêneros (MELLO, PERILO, BRAZ e PEDROSA, 2011) ${ }^{5}$. A LGBTfobia deve ser compreendida como um conjunto de crenças e mecanismos contrários as expressões sexuais e de gênero não enquadradas nas normas de gênero pressupostas pela cisheterossexualidade e das quais resultam violências físicas (atingindo a integridade do corpo do indivíduo) e/ou simbólicas (xingamentos, tratamento diferenciado e impedimento de participação em instituições, entre outros) (FREIRE e CARDINALI, 2012).

Ainda para Freire e Cardinali (2012) a expressão da LGBTfobia assume duas modalidades de apresentação: a pessoal (de caráter afetivo e manifestada por meio da rejeição aos homossexuais) e a cultural (na qual a homossexualidade é repudiada como um fenômeno social). Desse modo, uma sociedade

5 Apesar de não ser consensual dentre os diversos atores (individuais e coletivos) das militâncias de minorias sexuais cada vez mais o neologismo LGBTfobia vem sido utilizado. 
transhomofóbica viola os direitos humanos do(s)pertencente(s) à(s)comunidade(s) LGBT+. Segundo o Grupo Gay da Bahia em 2016 foram documentados no Brasil 343 assassinatos de gays, lésbicas e travestis; ademais, a cada aproximadamente 25 horas um indivíduo LGBT+ é assassinado no Brasil (cujos dados estão provavelmente subnotificados), situando o país como um dos mais transhomofóbicos do planeta (GRUPO, 2017).

A LGBTfobia neste sentido e transpondo-a para o jargão proposto por Michel Foucault (CASSAL e BICALHO, 2011; RABINOW e ROSE, 2006) pode ser compreendida como sendo uma tática de biopoder (intervenções sobre as características vitais particulares dos indivíduos) inserida numa estratégia biopolítica mais ampla (intervenções sobre as características sociais) típica da contemporaneidade, isto é, as relações de poder são generificadas em termos cisheterossexuais com o argumento de fortalecer biologicamente a espécie, alegando que os não cisheterossexuais destruirão a estrutura e valores familiares considerados normais. Em suma, trata-se da produção generalizada do medo como estratégia de dominação social (SAFATLE, 2016).

Desse medo decorrem sistemas educacionais tradicionais (do ponto de vista dos valores morais), intervenções medicamentosas e psicológicas para os não cisheterossexuais que são condenados a uma política da supressão e do desaparecimento, numa "injunção ao silêncio, afirmação da inexistência e, consequentemente, a constatação de que, em tudo isso, não há nada para dizer, nem para ver, nem para saber" (FOUCAULT, 2014, p. 8). Isso significa que além da busca ativa pelos heterodissidentes a fim de corrigi-los e puni-los, eles não raro preferem o silêncio e o "passar despercebido" como meios de minimização dos riscos (BLAIS, GERVAIS e HEBERT, 2014).

Mas há os que resistem e lutam contra a LGBTfobia. De acordo com Cassal e Bicalho (2011), Prado e Machado (2012) e Preciado (2011), os movimentos LGBT+ (assim como os movimentos negros e os feministas) passaram a lutar pelos seus direitos como cidadãos e a se afirmar dentro de uma cultura preconceituosa alegando sua existência e multiplicidade. Santos (2010) enfatiza que a resistência é uma forma de luta e militância política que pretende modificar o império da cisheterossexualidade, garantindo diferentes alternativas de vida e de autodeterminação de gênero e sexualidade. Nunca é demais destacar que a comunidade LGBT+ luta para efetivar direitos previstos em lei e não para obter privilégios (CARRARA, 2010; DIRETORIA, 2013). Isso é significativo na medida em que as políticas das visibilidades expandem o "campo democrático, que deveria ter como princípio a emergência de novos sujeitos políticos que introduzem uma dinâmica de democratização nas relações de poder" (PRADO e MACHADO, 2012, p. 118) e que potencializam a proteção e o direito à vida digna além da superação do preconceito (internalizado ou externo) e as suas consequências (CASSAL e BICALHO, 2011).

Desse modo, essa pesquisa teve como objetivo compreender como aguns integrantes de movimentos LGBT+ lidam (significam e enfrentam) com 
a LGBTfobia, investigando como ela afeta seus relacionamentos afetivos e sua vida acadêmica/profissional.

\section{Aspectos Metodológicos}

Esta é uma pesquisa do tipo empírica exploratória, transversal e qualitativa em Psicologia, o que permite compreender os significados que os sujeitos/ grupos atribuem para fenômenos sociais (CRESWELL, 2010; NEVES, 1996).

Essa pesquisa foi aprovada pelo Comitê de Ética em Pesquisa da universidade dos pesquisadores (CAAE 55759416.6.0000.5154 na Plataforma Brasil). Num primeiro momento o número de participantes seria definido de acordo com o critério de saturação de dados (FONTANELLA, RICAS e TURATO, 2008; FONTANELLA, LUCHESI, SAIDEL, RICAS, TURATO e MELO, 2011) respeitando os seguintes critérios de inclusão: não identificação como heterossexuais; idade igual ou superior a 18 anos; ter sido vítima de LGBTfobia; participar de algum movimento LGBT+. Mas essa estratégia de composição da amostra sofreu modificações devido às dificuldades de recrutamento de participantes. Inicialmente, possíveis participantes foram acessados primeiro junto a uma organização não governamental (ONG) que apoia a comunidade LGBT+ (que seria o cenário exclusivo desta pesquisa) e depois junto a um Coletivo LGBT+ de uma universidade pública federal, ambas situadas na região do Triângulo Mineiro. Essa alteração foi necessária porque apenas dois integrantes da organização não governamental aceitaram participar da pesquisa; assim, o coletivo ligado à universidade foi procurado, do qual resultaram mais quatro entrevistas, totalizando seis entrevistas $^{6}$. Foi apresentada a proposta de pesquisa para as respectivas coordenações (da organização não governamental e do coletivo) que firmaram parceria com os pesquisadores (por meio de carta de aceite) e que a divulgou aos seus integrantes; os que aceitaram participar foram acessados para a realização da entrevista. Trata-se, portanto, de uma amostra composta por conveniência.

As principais características dos participantes são as seguintes (os nomes são fictícios): Maria Clara, 29 anos, mulher transexual, heterossexual e analista de marketing, participante da ONG; Miguel, 27 anos, homem transexual, heterossexual e fabricante de placas, participante da ONG; Jack, 21 anos, homem cisgênero, bissexual, estudante, participante do Coletivo; Gabriel, 21 anos, homem cisgênero, homossexual, estudante, participante do Coletivo; Ana, 21 anos, mulher cisgênera, homossexual, desenhista de projetos de engenharia, participante do Coletivo; Tilda, 25 anos, mulher cisgênera, homossexual, marinheira fluvial de convés, participante do Coletivo.

Para a coleta de dados foi realizada uma entrevista semiestruturada com roteiro de questões elaborado pelos pesquisadores com base na literatura da área. Todas as entrevistas foram audiogravadas com autorização dos partici-

6 Após a primeira rodada de coleta de dados (da qual resultaram as seis entrevistas) os pesquisadores procuraram novamente a ONG e o Coletivo para novas entrevistas. Todavia, neste ínterim, a ONG encerrou suas atividades e foi fechada, e nenhum outro participante do Coletivo concedeu entrevista. 
pantes e tiveram duração aproximada de uma hora cada. Para garantir o sigilo de identidade dos participantes as entrevistas ocorreram em locais decididos de comum acordo entre entrevistadores e participantes. A entrevista estava composta por duas seções: a primeira com questões de caracterização dos participantes (aspectos sociodemográficos; idade; sexo; gênero; orientação sexual; escolaridade; ocupação; estado civil); a segunda seção contava com 12 questões sobre os seguintes temas: revelação pública da orientação sexual ou identidade de gênero (coming out $t^{7}$ ); LGBTfobia e relação com o agressor; influência da LGBTfobia nos relacionamentos amorosos e nos ambientes escolares e de trabalho; participação em movimento social LGBT+ e enfrentamento da LGBTfobia.

As informações das entrevistas foram organizadas a partir de uma análise de conteúdo temática cujas categorias foram construídas a posteriori a partir de critérios de semelhança semântica dos conteúdos do conjunto das entrevistas (CRESWELL, 2010). O referencial teórico utilizado é o de Michel Foucault acerca do dispositivo da sexualidade.

\section{Apresentação e discussão dos resultados}

Os dados coletados foram organizados em três categorias, a saber: (1) Cisheterossexualidade, LGBTfobia e sofrimento (que discorre sobre as dificuldades dos participantes num sistema social cisheterossexual); (2) Coming out e violências (que discorre sobre o impacto do assumir publicamente a orientação sexual e/ou identidade de gênero não cisheterossexual); e (3) Apoio dos movimentos sociais (que aborda as vivências dos participantes nos movimentos LGBT+).

Categoria 1 - Cisheterossexualidade, LGBTfobia e sofrimento

Em A História da Sexualidade l: a vontade de saber, Foucault (2014) argumenta que a sexualidade enquanto um dispositivo congrega relações de saberes e de poderes (reais e simbólicos) e uma série de discursos que articulam - a partir da heterossexualidade - sexo/biologia, gênero/papéis e orientação sexual, cuja intencionalidade é o controle dos indivíduos e das coletividades. Neste sentido, foram elegidos quais especialistas (nominalmente, psiquiatras, juristas e educadores) poderiam determinar o que seria normal para a sexualidade.

Portanto, não basta que o sujeito fale sobre suas atitudes sexuais, pois ele deve igualmente averiguar de que maneira elas se adéquam ao pressuposto normativos estabelecidos por parte dos interlocutores qualificados (especialistas) para codificar e avaliar tais discursos e práticas. $O$ fato é que esses discursos normativos servem de balizas para a educação (formal e informal) e são distribuídos e esperados pelas instituições, por exemplo, pelas famílias. Exemplo disso é o relato de Miguel: "desde criança sempre usei roupas masculinas, tênis, minha mãe brigava comigo para mim [sic.] me vestir mais feminino, só que eu nunca consegui". E também quando Maria Clara e Ana afirmaram 7 Outness é o processo no qual a pessoa assume (para si própria) e passa a se reconhecer como homossexual ou transgênero. Coming out é o processo no qual a pessoa revela publicamente seu outness. 
sobre seu ambiente de trabalho:

Eu trabalho no ramo de eventos, a maioria das parcerias, dos parceiros terceirizados que prestam serviços, são homens velhos, sistemáticos, de igreja, de fazenda, que me tratavam no respectivo nome que eles conheceram há dez anos. E eu falei pronto, agora eu vou ter que bater de frente, eu vou ter que chegar e falar: olha, aquele menino lá não existe mais, agora sou eu, não existe mais aquela pessoa. E isso foi muito difícil, muito difícil. Hoje ainda tem pessoas que me tratam com o nome ao qual meus pais me deram. (Maria Clara)

Ele [patrão] disse que tinha que demitir alguém. E eu senti que foi porque eu não me encaixava nos padrões que ele queria para empresa dele, que era uma empresa familiar, tinha toda aquela coisa e eu senti que foi por isso. (Ana)

Ainda pode ser notada a relação de poder de quem está autorizado a regular a sexualidade quando Ana relatou a dinâmica de sua família e de sua escola de ensino médio:

Os meus pais descobriram, eles são muito preconceituosos e religiosos e meu pai é um cara muito difícil. Meu pai me mantinha em cárcere privado. Eu ia para escola e para casa, para escola e para casa, para escola e para casa. Já ouvi em escola que não poderia usar o mesmo banheiro enquanto tivessem meninas lá, porque os pais estavam reclamando, porque eu sempre fui a única lésbica assumida da escola. (Ana)

Estes trechos de entrevistas destacam que as instituições (família e escola) estipulam e/ou replicam normas sobre como a sexualidade dos sujeitos deve ser vivenciada para ser considerada normal. De acordo com Miskolci (2009) a heteronormatividade compulsória (conceito aproximado da cisheterossexualidade) é um conjunto de regras que fundamenta os processos sociais de regulação e controle do corpo social e sexual, caracterizando-se por ser uma denominação contemporânea que evidencia o dispositivo histórico da sexualidade pressuposto por Foucault: todos devem ser heterossexuais por ser este o modelo natural da sexualidade. Aos que não cumprem essas exigências são reservadas punições e intervenções - por exemplo, como relatou Tilda acerca de uma das violências que sofreu:

Então, eram mais ou menos uns dez adolescentes e eles já vieram assim atrás de mim, eu percebi que ia ser atacada e eles já vieram apertando o passo [sic.]. Tipo assim, me xingando e falando que iam me transformar em mulher, em realmente mulher e tal e começaram a tacar pedra e objetos que acharam na rua e então eu corri, Mas conseguiram me atingir uma pedra na costela, do lado esquerdo, uma na perna e outra no ombro. (Tilda) 
No trecho anterior o "transformar em mulher" (Tilda é uma mulher cisgênera homossexual) nada mais quer dizer que a participante pode ser normalizada por meio da violência (hetero) sexual que, aos olhos dos agressores, não é considerada uma violência, mas sim um auxílio interventivo calcado na lógica cisheterossexual que pretende readequar a orientação sexual da participante considerando seu sexo/gênero (fêmea/mulher que, por isso, necessariamente deveria gostar de homens), cujo discurso de normalização se justifica num pressuposto de fixidez de papéis que homens e mulheres devem desempenhar. Nesse sentido, Butler (2015) destaca a misoginia e a LGBTfobia que fundamenta a dominação masculina.

O relato de Tilda destaca não apenas a homofobia motivada pela orientação sexual (homossexual), mas também a de gênero (é uma mulher homossexual). Também se nota essa violência quando Ana relatou que suspeita ter sido demitida de seu emprego

Por ser uma mulher lésbica. Foi bem na época que cortei meu cabelo. Eu, quando entrei lá, eu tinha o cabelo grande. Foi na época que eu estava começando a mudar o meu estilo, o meu jeito. Eu estava me identificando mais [com a orientação homossexual] e foi quando isso [demissão] aconteceu.

A cisheterossexualidade também impacta os relacionamentos afetivos dos participantes, como relatou Maria Clara (mulher transexual - ou seja, nasceu biologicamente homem, porém psicologicamente se identifica com o gênero feminino) com orientação heterossexual (ou seja, tem predileção por parceiros do sexo/gênero masculino), fato que no geral causa consternação:

Um relacionamento ou uma relação afetiva que você não se enquadra perante as outras em sociedade, você é vítima de apontamentos e definições. Eu me relacionando com um homem trans, um casal transhetero, as pessoas na rua olham e falam: 'Nossa, o que é aquilo?'. (Maria Clara)

Essa cisheterossexualidade diferentemente da análise da sexualidade proposta por Foucault (2014) e das teorias queer (BUTLER, 2015) considera o indivíduo como um sujeito cartesiano autônomo que possui uma identidade inata que existe independentemente da sociedade e das suas relações de poder (SPARGO, 2017). Mas, pelo contrário, sexo, gênero e orientação sexual não possuem nem relações lineares nem estáveis, e são resultados de complexas construções sociais mediadas por relações de poder que representam interesses de grupos. E esses discursos e práticas que estipulam uma normalidade para a sexualidade pertencem a instituições que apregoam uma cisheterossexualidade - e aqueles que não se enquadram não apenas sofrem violências

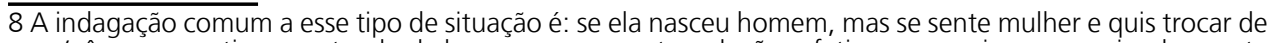
sexo/gênero e continua gostando de homens para manter relações afetivas e sexuais, porque simplesmente não assumiu sua homossexualidade? - o que já seria considerado um desvio. 
reais, mas vivem com medo de sofrerem violências, como relataram alguns participantes:

Aquela coisa de medo de andar na rua de mão dada, medo de demonstrar afeto em público e ser atacada de alguma forma. (Ana)

Eu estava de mãos dadas com meu ex-namorado aqui em [cidade], estava indo para o cinema e aí buzinaram. Passou um carro rápido, cheio de caras e aí buzinaram e gritaram algumas coisas que eu nem quis assimilar e meu namorado ficou meio constrangido, a gente tirou as mãos e foi andando para o cinema sem as mãos dadas. Me senti triste. (Jack)

Você ser gay e também ser amigo de uma outra pessoa que também é gay e seja mais afeminado, você meio que já pensa assim que se você andar com ele na rua, vai passar um cara e te xingar.(Gabriel)

Você está doido para ir no banheiro e não tem aquele banheiro específico, social, então você tem que entrar ou no feminino ou no masculino. Na questão [sic.], você vai ao feminino, porque você sabe que às vezes, a única coisa que elas vão fazer é gritar e mandar você ir embora. Agora no masculino, você entra e você é espancado, entendeu? Ou estuprado, no caso. É difícil. (Miguel)

É bem complicado isso, porque ou você tem que ir e parecer muito e passar desapercebida ou você ainda vai ser alvo de alguma coisa. No meu caso, ainda mata. Mulher com 1,84 metros de altura, mulheres trans, travestis, então já chamam atenção por si só, então cabe a cada uma ser o que deseja ser e tentar se camuflar, vamos dizer assim, para evitar isso, tantos transtornos, todos. (Maria Clara)

E a última vez que fui em [cidade]. Tem muita diversidade lá, cultural, em todos os âmbitos, mas eu nunca pensei que em um final de semana, em dois dias, eu seria atacada de tal forma [perseguida e agredida verbalmente], intensa assim. (Tilda)

Assim, é importante considerar que a LGBTfobia (e a cisheterossexualidade) operam não somente por meio de práticas reais e efetivadas de violências, mas também por intermédio de um efetivo gerenciamento dos afetos (o medo de ser violentado) que é extremamente eficaz e eficiente (SAFATLE, 2016), interpondo uma política do silenciamento e do ocultamento das heterodissidências. Por isso, os relatos dos participantes retrataram não apenas às pressões sofridas (violências e LGBTfobia) para se enquadrarem em uma sexualidade considerada normal, mas também seus sofrimentos públicos e privados.

\section{Categoria 2 - Coming out e violências}

Devido ao império da cisheterossexualidade representada pela LGBTfo- 
bia descrita na seção anterior, os participantes afirmaram perceber como as inadequações às normas de gênero e sexualidade acarretaram sofrimentos e dificuldades. Estes relacionam-se com as significações sociais atribuídas a respeito das (pré) condições de ser mulher ou homem, pois a cisheterossexualidade obriga as pessoas a apenas dois caminhos possíveis: ou assumem os papéis e estereótipos dos gêneros designados (ser homem ou ser mulher) ou terão que pagar considerável preço para dar vazão aos seus desejos e vontades (GUIMARÃES, 2009).

Pode-se notar o custo pessoal desses processos (transmutado em sofrimentos, confusões, violências) nos seguintes relatos:

E eu sempre vi que tinha alguma coisa errada, não tinha certeza do que era. Não sou aquilo que estão me enquadrando ser, só que eu não sabia me questionar sobre isso e de certo modo, fui vivendo perante o que a sociedade intitula. (Maria Clara)

No início é muito difícil, sabe? De você aceitar o que você é, vem de todos os lados, você escuta coisas [sic.], as pessoas falando tipo 'olha ali aquele viadinho, olha aquela sapatão', então, é complicado assim, você meio que sabe o que você é, só que você não se aceita por conta dessas coisas, sabe?(Gabriel)

Foi meio confuso por parte de todo o ambiente social que falava, fala, até hoje fala. Então assim 'será que isso realmente é normal? Eu sou anormal?' Coisas do tipo, sabe? Então por isso que fiquei na oscilação de tipo assim, tanto ficar com menino, quanto ter tido relação com menina também. (Tilda)

Assumir identidade de gênero e/ou orientação sexual discrepante da cisheterossexualidade foi vivenciado pelos participantes ou como exercício de libertação ou como confirmação do sofrimento e de prováveis violências. Essa dualidade relatada pelos participantes encontra respaldo na literatura científica e parece ser típica no processo de coming out (NASCIMENTO e SCORSOLINI-COMIN, 2018). Situando o processo de coming out como uma questão de gênero Connell (2006) argumenta que se (a identidade de) gênero e orientação sexual são resultados das relações sociais, reconhecer possibilidades discrepantes da denominada normalidade é fundamental para essas pessoas, pois as legitima enquanto sujeitos e atores sociais. Aliás, o coming out pode ser compreendido à luz dos argumentos de Foucault (2014), isto é, como uma das práticas da confissão da sexualidade que na modernidade ocidental é vista como uma técnica para se produzir a verdade sobre o sujeito:

Um ritual onde a verdade é autenticada pelos obstáculos e as resistências que teve de suprimir para poder manifestar-se, enfim, um ritual onde a enunciação em si, independentemente de suas consequências externas, produz em quem a articula manifestações intrínsecas: inocenta-o, resgata-o, livra-o de suas faltas, libera-o, promete-lhe a salvação. (FOUCAULT, 2014, p.69) 
Contraditoriamente, a confissão pretende promover a libertação do sujeito situando-o numa estrutura de adequação/opressão social, haja vista que o relato do sujeito precisa passar pela apreciação do outro especialista que Ihe aferirá validade e adequação. Mas a partir desse momento de reconhecimento social, mesmo que de maneira negativa e opressora, ao ser situado socialmente o (participante) heterodissidente poderá reclamar seus direitos (GUIMARÃES, 2009). A sensação de liberdade resultante da confissão (de não ser cisheterossexual) constou em alguns relatos dos participantes:

E aí quando eu fui me assumir eu fiquei 'ah, que tem as pessoas falarem? Então, falem, né?' Falem bem ou falem mal, falem de mim [risos]. (Jack)

Me deixou mais liberto comigo mesmo. Antes eu não conseguia ser tão próximo das pessoas, tipo assim, de amizade e quando eu consegui me assumir, eu consegui conversar mais com ele [amigos heterossexuais] sobre a vida em geral, então, foi bem legal pra mim. Foi bem legal, tirou um peso das minhas costas. (Gabriel)

Não se pode, contudo, acreditar ingenuamente que a confissão terá sempre um efeito de liberação e aceitação social do sujeito, pois como afirma Foucault (2014) o confessar também está inserido e é um dos dispositivos de poder uma vez que dizer o que se é, se faz, se pensa, se esconde e oculta (no caso, não estar adequado aos ditames da sexualidade padrão) fornece argumentos ao outro para a produção de intervenções para (re) colocar o confessor na trama dos dispositivos de poder.

No caso dos participantes isso pode ser notado quando eles relataram não apenas a dificuldade de assumirem a heterodissidências para si mesmos (outness), mas principalmente quando do receio de sofrer violências a partir do momento em que assumiram suas heterodissidências no espaço público (coming out):

Para mim foi sabe, um medo. De não aceirarem e tudo mais. Então eu tomei vários calmantes para mim [sic.] falar, sabe? Primeiro momento com minha mãe, meu pai e meu irmão foi complicado, principalmente com meu pai e meu irmão. Minha mãe já tinha depressão antes de ela ter descoberto e quando eles [pai e irmão] ficaram sabendo, eles jogaram a culpa totalmente em mim. (Tilda)

Me assumir para mim já foi uma mudança enorme, porque era uma coisa que eu não imaginava que existia e quando eu descobri que isso existia, quando eu comecei a me descobrir, a aflorar minha sexualidade, que eu descobri que era isso que eu queria, que era isso que eu era, mudou tudo. Até eu conseguir me aceitar, levou um tempo para eu conseguir me aceitar, mudou tudo para mim. E depois com minha família. Já cheguei a ir para o hospital de tanto apanhar [do meu pai]. Já aconteceu muita coisa pesada, muita coisa pesada. (Ana) 
Segundo Nascimento e Scorsolini-Comin (2018) outness e coming out são processos independentes, mas ambos podem distribuir consequências similares: LGBTfobias (intra e extrafamiliares), autorrecriminações e culpabilizações etc. Tudo isso porque de acordo com Foucault (2014) o sexo, desde a penitência cristã, é matéria privilegiada da confissão. Essa confissão - pelos relatos dos participantes - pode de fato libertar o sujeito quando ele se encontra em um ambiente acolhedor e seguro, mas quando o ambiente é transhomofóbico pode causar sofrimento físico e psicológico. Segundo os participantes destacou-se nesse processo de confissão a quase completa ausência de suporte familiar. Por isso, eles relataram a necessidade das redes sociais extrafamiliares de proteção.

Categoria 3 - Apoio dos movimentos sociais

Em meados dos anos 1970 os ativismos políticos e os movimentos sociais para a libertação gay e demais minorias contestaram a representação do desejo e as relações entre pessoas do mesmo sexo como algo não natural e/ou doentio. O objetivo daquele ativismo foi transformar o sistema social opressor e mantenedor de privilégios para alguns grupos a partir de uma perspectiva (relacional) de gênero e sexualidade. Assim, não apenas realizaram campanhas e manifestações por justiça e direitos individuais e sociais igualitários para as denominadas minorias sexuais, mas também aos poucos constituíram espaços de proteção e discussão destas questões, resultando nas denominadas comunidades e movimentos LGBT+ (SPARGO, 2017).

De acordo com Toledo e Filho (2013) as consequências da violência LGBTfóbica para as pessoas LGBT+ depende fundamentalmente da relação entre acesso e dificuldades de acesso aos sistemas e redes de apoio efetivos e confiáveis. Por isso, segundo Gohn (2011) é significativo o papel dos movimentos sociais que podem estabelecer ações coletivas de resistência à exclusão, além de lutarem pela inclusão social dos heterodissidentes. Por meio de discursos e práticas os movimentos LGBT+ estabelecem espaços para criação de identidades coletivas para pessoas que, outrora excluídas, podem passar a se sentir incluídas dentro de um grupo ativo de proteção.

Os movimentos sociais ainda atuam como uma estratégia da organização da ação coletiva, atuando no sentido de construir alianças, laços de solidariedade e de pertencimento entre as pessoas engajadas em uma mesma causa - no caso a LGBT+ e o combate à LGBTfobia produzida pela cisheterossexualidade. Desse modo, esses movimentos devem ser compreendidos como processos sociais de constituição de valores e ações que estabelecem formas de pertença grupal e sustentação de uma dada realidade social, no caso a anti LGBTfobia (MACHADO e PRADO, 2005).

Durante as entrevistas foi unânime entre os participantes que o modo como lidavam com a LGBTfobia passou por modificações principalmente após entrarem e passarem a participar ativamente de algum movimento social LGBT+ (no caso, a ONG ou o Coletivo): 
Entrei e foi assim uma maravilha, eu me vi num lugar onde eu não estava sozinha! Onde tinha um monte de gente que passava coisa parecida ou pior que a minha, e a gente conseguia rir disso tudo. Enquanto a gente não tendo esse apoio, a gente só fazia chorar, só fazia se trancar. E realmente ali [ONG] eu vi que, poxa, eu sou assim, tem mais pessoas assim, eu vou mais me aceitar e vamos dar a cara a tapa. (Maria Clara)

A partir do momento que você tem um conhecimento e um apoio, tudo muda. Tem mais segurança. (Miguel)

Você convive com um monte de gente que já sofreu muita coisa e eles contarem isso, externaliza não só deles para a gente, a gente escutar e ver que isso. Você tem que se aceitar e pronto! Não vai ser uma pessoa falando alguma merda para você que isso vai te afetar, então isso me ajudou bastante. Porque eles [companheiros de movimento] têm esse contato e eles estão vendo como que é, então assim, aceitação, não aceitação. Eles entendem a gente com uma facilidade muito maior do que com as pessoas que não estão dentro do movimento. (Gabriel)

Quando eu for sofrer alguma coisa desse jeito, eu sei que tem um monte de gente que estaria disposto a lutar contra isso, então não é uma coisa, tipo, que vai me abalar ou que vai me deixar ali sozinho. Se eu sofrer algo, saber que vai ter gente fisicamente pra me ajudar nesse sentido. (Jack)

É uma coisa diferente, realmente. É um apoio incondicional independente de qualquer coisa, são pessoas que a gente sabe que vão estar ali, que te apoiam. (Ana)

É bem impactante pra quem tá no coletivo, acho importantíssimo, sabe? Para nós mesmos que somos homossexuais, saber que tem um apoio maior, entender de várias coisas que até sejam novas para nós mesmos e levar isso adiante, entrar numa luta para estar fortalecendo e para evitar que outras pessoas sejam vítimas - até de si mesmas, entendeu? (Tilda)

Por meio desses relatos percebe-se que para os participantes os movimentos sociais LGBT+ não são apenas espaços macropolíticos de discussão sobre a hierarquização e as múltiplas formas de inferiorização as quais a comunidade LGBT+ estão sujeitas (PRADO e MACHADO, 2012), mas também se configuram como espaços micropolíticos potencializadores da vida - numa estratégia de biopolítica. Em suma, são espaços nos quais os participantes estabelecem redes de apoio consideradas confiáveis que não somente lutarão por seus direitos, mas também acolherão seus sofrimentos privados.

O acolhimento que acontece dentro desses espaços é necessário à medida em que a família nem sempre se configura como promotora do bem-estar dos sujeitos heterodissidentes (por exemplo, no caso de Ana, citado anteriormente, as violências físicas eram promovidas pelo próprio pai) - aliás, 
pelo contrário: não raro os familiares promovem situações constrangedoras e dolorosas para os sujeitos que, assim, buscam por apoio em outras redes. A violência intrafamiliar, portanto, por vezes replica a violência LGBTfóbica (PERUCCHI, BRANDÃO e VIEIRA, 2014).

Por fim, de acordo com Gorisch (2014) garantir e proteger os direitos relacionados ao exercício da sexualidade e da autodeterminação do gênero significa tentar garantir o direito humano fundamental do direito à vida. Por isso, diante os poucos e limitados esforços do Estado neste quesito resta à sociedade civil e aos movimentos sociais tomarem essa responsabilidade quando outras instituições (no caso, a família e a escola) não garantem esse direito. Esse espaço criado no terceiro setor torna-se um campo e um cenário nos quais os heterodissidentes podem se fazer ouvir e existir, fortalecendo suas demandas, suas necessidades, sua luta por direitos e busca por alternativas num contexto vulnerável repleto de riscos e violências. Por fim, os movimentos sociais LGBT+ colocam-se como a possibilidade de luta e garantia dos direitos humanos.

\section{Considerações Finais}

Este artigo pretendeu apresentar uma discussão sobre dois âmbitos: (1) como a LGBTfobia afeta a vida privada e pública dos sujeitos, e (2) se participar de um movimento LGBT+ auxilia no enfrentamento dessas adversidades. Compreender como integrantes de movimentos LGBT+ lidam (significam e enfrentam) com o preconceito transhomofóbico é significativo porque há de se destacar que essa modalidade de violência impacta negativamente suas vidas: ao assumirem para si próprios (outness) ou relatarem publicamente (para familiares e/ou amigos) (coming out) duas discrepâncias para com a cisheterossexualidade os participantes se sentiram mal, culpados e/ou temerosos de sofrerem algum tipo adicional de violência intrafamiliar ou no espaço público.

A LGBTfobia também afetou seus relacionamentos afetivos à medida que alguns participantes evitaram tornar visível suas heterodissidências (por exemplo, evitam andar de mãos dadas na rua com seus parceiros por medo de sofrer violência), preferindo à reclusão ou o silenciamento da autodeterminação de gênero e orientação sexual. Nesse cenário (local e nacional) de violências e sofrimentos participar de algum grupo ou movimento LGBT+ equivale à tentativa de procurar por uma rede de apoio que auxilie no enfrentamento da LGBTfobia - estes cenários pretendem ser espaços seguros de acolhimento e, consequentemente, potencializadores da vida e dos direitos que todo e qualquer cidadão deve possuir.

Os participantes desta pesquisa são jovens adultos, todos com ensino médio completo, inseridos no mercado de trabalho e/ou numa universidade pública e integrantes de movimentos sociais que procuram fomentar e fortalecer o ativismo pelos direitos LGBT+. Esse perfil diz respeito das condições distintas que possuem para enfrentar a violência transhomofóbica. Neste sen- 
tido, seria importante também considerar sujeitos que não possuem estas condições (além de outras particularidades relacionas à classe social, etnia/raça, orientação religiosa etc.) que - longe de serem privilégios ou facilitadores para enfrentar a LGBTfobia - são elementos adicionais que podem contribuir para este enfrentamento. Talvez seja este o principal limite desta pesquisa.

Mediante os resultados apresentados pelas entrevistas destaca-se a importância das entidades coletivas (governamentais ou não) dos mais diversificados setores das políticas públicas e da proteção social oferecerem condições adequadas para que os movimentos sociais tenham garantido seu espaço de atividade política - ainda mais num contexto atual no qual a perda dos seus direitos parece ser tônica. Esse reforço de visibilidade e de condições de trabalho contínuo é extremamente importante, podendo ser exemplificado por um (triste) fato pertinente a esta pesquisa: coincidentemente logo ao final da coleta dos dados na ONG esta finalizou suas atividades por falta de recursos materiais, financeiros e de recursos humanos qualificados e por falta de incentivos públicos, desarticulando todo apoio que fornecia as pessoas que sofriam violências transhomofóbica. Esse fechamento pode ser compreendido como parte integrante de um discurso de poder que atende às demandas tradicionalistas (de sexualidade e de gênero) que enaltecem a cisheterossexualidade.

Por fim, os movimentos sociais têm que lutar não apenas para a conquista de políticas públicas e para ser ancoradouros àqueles que já foram ou estão na iminência de serem violentados, mas também necessitam lutar para simplesmente existir.

\section{Referências bibliográficas}

BLAIS, Martin; GERVAIS, Jesse \& HEBERT, Martine. Internalized homophobia as a partial mediat or between homophobic bullying and self-esteem among youths of sexual minorities in Quebec (Canada). Ciênc. saúde coletiva, v.19, n.3, p.727-735, 2014.

BUTLER, Judith. Problemas de Gênero. Rio de Janeiro, Civilização Brasileira, 2015.

CARRARA, Sérgio. Política e direitos sexuais no Brasil Contemporâneo. Bagoas, n.5, pp.131-147, 2010.

CASSAL, Lucas Carpes Barros \& BICALHO, Pedro Paulo Gastalho (2011). Homofobia e sexualidade: o medo como estratégia de biopoder. Revista de Psicologia da Unesp, v.10, n.2, pp.57-64, 2011.

CONNELL, Raewyn. Gênero em Termos Reais. São Paulo, NVersos, 2016.

CRESWELL, John Willian. Projeto de Pesquisa: Métodos qualitativo, quantitativo e misto. Porto Alegre, Artmed, 2010.

DIRETORIA NACIONAL DO CEBES. Saúde para grupos LGBT exige a radicalização democrática. Saúde em Debate, v.37, n.98, pp.366-371, 2013.

FOUCAULT, Michel. História da Sexualidade I: A Vontade de Saber. Rio de Janeiro, Edição Graal, 2014.

FONTANELLA, Bruno José Barcellos; RICAS, Janete \& TURATO, Egberto Ribeiro. Amostragem por saturação em pesquisas qualitativas em saúde: contribuições teóricas. Cadernos de Saúde Pública, v.24, n.1, pp.17-27, 2008.

FONTANELLA, Bruno José Barcellos; LUCHESI, Bruna Moreti; SAIDEL, Maria Giovana Borges; RICAS, Janete; TURATO, Egberto Ribeiro \& MELO, Débora Gusmão. Amostragem em pesquisas qualitativas: proposta de procedimentos para constatar saturação teórica. Cadernos de Saúde Pública, v.27, n.2, pp.389-394, 2011. 
INTEGRANTES DE MOVIMENTOS LGBT+ E ENFRENTAMENTO DA LGBTFOBIA

FREIRE, Lucas \& CARDINALI, Daniel. O ódio atrás das grades: da construção social da discriminação por orientação sexual à criminalização da homofobia. Sexualidad, Salud y Sociedad-Revista Latinoamericana, n.12, pp.37-63, 2012.

FRY, Peter \& MAC RAE, Edward. O que é homossexualidade. Brasiliense, 1991.

GOHN, Maria da Glória. Movimentos sociais na contemporaneidade. Revista Brasileira de Educação, v.16, n.47, pp.333-361, 2011.

GORISCH, Patrícia. O Reconhecimento dos Direitos Humanos LGBT. Curitiba, Appris, 2014.

GOUVEIA, Raimundo \& CAMINO, Leôncio. Análise Psicossocial das visões de ativistas LGBT sobre família e conjugalidade. Psicologia Política, v.9, n.17, pp.47-65, 2009.

GRUPO GAY DA BAHIA. Assassinato de LGBT no Brasil: Relatório 2016. 2017. Available on: https:// homofobiamata.files.wordpress.com/2017/01/relatc3b3rio-2016-ps.pdf. Access date: July, 06th.2017.

GUIMARÃES, Anderson Fontes Passos. O desafio histórico de 'tornar-se um homem homossexual': um exercício de construção de identidades. Temas em Psicologia, v.17, n.2, pp.553-567, 2009.

JOYCE, Karla. Histórico do PLC122/2006. (s/d). Avaiable on: http://www.plc122.com.br/historicopl122/\#axzz3K6rWn25M. Access date: July, 06th.2017.

MACHADO, Frederico Viana \& PRADO, Marco Aurélio Máximo. Movimentos homossexuais: a constituição da identidade coletiva entre a economia e a cultura. O caso de dois grupos brasileiros. Interações, v.10, n.19, pp.35-62, 2005.

MELLO, Luiz; PERILLO, Marcelo, BRAZ; Camilo Albuquerque de \& PEDROSA, Cláudio. Políticas de saúde para lésbicas, gays, bissexuais, travestis e transexuais no Brasil: em busca de universalidade, integralidade e equidade. Sexualidad, Salud y Sociedad-Revista Latinoamericana, n.9, pp.7-28, 2011.

MISKOLCl, Richard. A Teoria Queer e a Sociologia: o desafio de uma analítica da normalização. Sociologias, v.11, n.9, pp.150-182, 2009.

NASCIMENTO, Geysa Marcelino \& SCORSOLINI-COMIN, Fabio. (2018). A revelação da homossexualidade na família: revisão integrativa da literatura científica. Temas em Psicologia, v.26, n.3, pp.1527-1541, 2018.

NEVES, José Luiz. Pesquisa qualitativa - características, usos e possibilidades. Caderno de Pesquisa em Administração, v.1, n.3, pp.1-5, 1996.

PERUCCHI, Juliana; BRANDÃO, Brune Coelho \& VIEIRA, Hortênsia Isabela dos Santos. Aspectos psicossociais da homofobia intrafamiliar e saúde de jovens lésbicas e gays. Estudos de Psicologia, v.1, n.19, 68-76, 2014.

PRADO, Marco Aurélio Máximo \& MACHADO, Frederico Viana. Preconceitos contra homossexualidades: a hierarquia da invisibilidade. São Paulo, Cortez, 2012.

PRECIADO, Beatriz. Multidões queer: notas para uma política dos anormais. Estudos Feministas, v.1, n.19. pp.11-20, 2011.

RABINOW, Paul \& ROSE, Nicolas. O conceito de biopoder hoje. Política \& Trabalho, n.24, pp. 27-57, 2006.

SAFATLE, Vladimir. O circuito dos afetos: corpos políticos, desamparo e o fim do indivíduo. São Paulo: Cosac-Naif, 2016.

SANTOS, Paulo Rei. Tensões e desafios: LGBTs e o poder público? Revista de Psicologia da Unesp, v.9, n.2, pp.147164, 2010.

SILVA, Sérgio Gomes da. Preconceito no Brasil Contemporâneo: as Pequenas Diferenças na Constituição das Subjetividades. Psicologia Ciência e Profissão, v.23, n.2, pp.2-5, 2003.

SPARGO, Tamsin. Foucault e a teoria queer. Belo Horizonte, Autêntica Editora, 2017.

TOLEDO, Lívia Gonsalves \& FILHO, Fernando Silveira Teixeira. Homofobia familiar: abrindo o armário 'entre quatro paredes'. Arquivos Brasileiros de Psicologia, v.65, n.3, pp.376-391, 2013. 